\title{
O pensamento de Eduardo Prado e a América hispânica como exterior constitutivo do Brasil em fins do século XIX e princípios do século $\mathrm{XX}$
}

\author{
Carlos Henrique Armani ${ }^{1}$ \\ Departamento de História/Programa de Pós-Graduação em História, \\ Universidade Federal de Santa Maria, Santa Maria, Rio Grande do Sul, Brasil
}

Resumo: Pretendemos investigar, neste artigo, o pensamento de Eduardo Prado, bem como de alguns de seus interlocutores, sobre a América Hispânica como exterior constitutivo do Brasil na virada do século XIX para o século XX. Trata-se de um período na história intelectual do/no Brasil que foi marcado pelas diversas instabilidades que a própria ideia de identidade mobilizava, resultando num esforço fracassado de reconstituir totalidades do passado e mesmo de garantias para o futuro. Entendemos que as disputas em torno das identidades e sua historicidade foram não somente um problema no âmbito político, como também, uma crise de valores e de sentido histórico que os autores finisseculares vivenciaram em termos de experiência histórica quando pensaram não somente o Brasil, mas um de seus principais exteriores constitutivos.

Palavras-chave: História Intelectual no Brasil; América Latina; Eduardo Prado; Séculos XIX e XX.

Título: El pensamiento de Eduardo Prado y la América hispana como un exterior constitutivo de Brasil a fines del siglo XIX y principios del XX

Resumen: Pretendemos investigar, en este artículo, el pensamiento de Eduardo Prado, así como de algunos de sus interlocutores, sobre la América Hispana como un exterior constitutivo de Brasil en el cruce del siglo XIX al siglo XX. Es un período en la historia intelectual de / en Brasil que estuvo marcado por las diversas inestabilidades que movilizó la idea misma de identidad, lo que resultó en un esfuerzo fallido de reconstituir totalidades del pasado e incluso garantías para el futuro. Entendemos que las disputas en torno de las identidades y su historicidad fueron no solo un problema en el ámbito político, sino también una crisis de valores y de significado histórico que los autores finiseculares experimentaron en términos de experiencia histórica cuando pensaron no solo el Brasil, sino uno de sus principales constituyentes exteriores.

Palabras clave: Historia intelectual en Brasil; América Latina; Eduardo Prado; Siglos XIX y XX.

Title: The thought of Eduardo Prado and the Hispanic America as constitutive outside of Brazil at the ends of 19th Century and beginnings of 20th Century.

Abstract: We intend to investigate in this article the thought of Eduardo Prado, as well as some of his interlocutors, about Hispanic America as a constitutive outside of Brazil at the turn of the 19th to the 20th century. This is a period in the intellectual history of/in Brazil that was

\footnotetext{
1 Doutor em História (Pontifícia Universidade Católica do Rio Grande do Sul); Pós-Doutorado em Teoria e Filosofia da História (Universidade Federal do Rio de Janeiro). Professor do Departamento de História e do Programa de Pós-Graduação em História da Universidade Federal de Santa Maria (UFSM). Orcid: https://orcid.org/0000-0003-4855-6115.
}

E-mail: carlosarmani@gmail.com. 
shaped by the various instabilities that the very idea of identity mobilized, resulting in a failed effort to reconstruct past totalities and even guarantees for the future. We understand that the disputes over identities and their historicity were not only a problem in the political sphere, but also a crisis of values and historical sense that the authors of the fin-de-siècle experienced in terms of historical experience when they thought not only Brazil, but one of its main constitutive outsides.

Keywords: Intellectual History in Brazil; Latin America; Eduardo Prado; 19th and 20th Centuries.

\section{Introdução}

Pretendemos investigar, neste artigo, o pensamento de Eduardo Prado, bem como de alguns de seus interlocutores, sobre a América Hispânica como exterior constitutivo do Brasil$^{2}$. Trata-se de um período na história intelectual do/no Brasil que foi fundamentalmente marcado pelas diversas instabilidades que a própria ideia de identidade mobilizava: fins do século XIX e início do século XX, período durante o qual o Brasil se tornou uma república e se afastou, ao menos em termos políticos, do seu modelo europeu. Escolhemos como objeto de interpretação o pensamento de Eduardo Prado não somente pela expressividade de suas ideias, como também em razão de ele ter sido um daqueles autores destacados como "polemistas irados e bacharéis em luta" (VENTURA, 1991, p. 13). A polêmica foi o modo como os debates em torno da nação e de outros temas se constituíram. Poucas palavras poderiam indicar melhor as disputas intelectuais do período que a palavra polêmica, em um momento carregado de tensões no campo intelectual, institucional e existencial das mais diversas comunidades imaginadas (ANDERSON, 2005) ${ }^{3}$. Contemporâneo de Prado, o crítico

\footnotetext{
${ }^{2}$ Eduardo Prado foi membro de uma rica família de cafeicultores de São Paulo e um dos principais intelectuais de fins do século XIX. Formou-se em Direito na Faculdade de São Paulo e trabalhou como jornalista e historiador. Prado ainda foi um dos fundadores da Academia Brasileira de Letras e sócio-correspondente do Instituto Histórico e Geográfico Brasileiro. Manteve sua vida dividida entre a fazenda do Brejão, no interior de São Paulo, e Paris. Não produziu uma obra muita extensa, em razão da morte prematura, de febre amarela, que interrompeu a sua carreira intelectual, aos 41 anos de idade. Em termos políticos, o escritor foi um dos principais articuladores do Partido Monarquista em São Paulo, posição política da qual ele jamais se desfez. Para o leitor interessado em sua biografia, recomendo a leitura de: (LEVI, 1974). De acordo com Veríssimo (1963, p. 292), na "literarura brasileira, Eduardo Prado tem duas singularidades: ser um dos poucos, senão o único homem rico e certamente o de mais valor que aqui se deu, sequer como diletante, às letras, e ser talvez em nossa literatura o único escritor reacionário". Para uma contextualização mais ampla dos intelectuais da virada do século, ver: (BROCA, 2005).

${ }^{3}$ Falar em comunidade imaginada nos remete-nos a Benedict Anderson. Apesar de sua teoria a respeito da nação como comunidade imaginada ser bem conhecida, vale a pena citá-la neste artigo. De acordo com o autor, a nação "é imaginada porque até os membros da mais pequena (sic) nação nunca conhecerão, nunca encontrarão e nunca ouvirão falar da maioria dos outros membros dessa mesma nação, mas ainda assim, na mente de cada um existe a imagem de sua comunhão". A afirmação de Anderson tem o mérito, entre outros, de apreender o movimento não-empírico que compõe a ideia de identidade, bem como a relação dessa construção com a representação do "muitos como um" da comunidade. Nessa direção, é pertinente aceitar a ideia de uma comunidade imaginada que forma um sistema de representação cultural do ser nacional e mesmo de outras comunidades que se antagonizam com ela. Ver: (ANDERSON, 2005, p. 25). Compreendemos a comunidade imaginada apenas como um esforço dos intelectuais aqui investigados em criar uma ideia de nação e mesmo de identidade continental, dentro de uma relação com uma série de outros que fazem da comunidade
} 
literário José Veríssimo o definiu como um "polemista vigoroso e agudo, um verdadeiro escritor em suma pelas peregrinas qualidades da sua ideação e expressão (VERísSIMO, 1963, p. 292)

Ao pensar a questão da identidade, de antemão lidamos com um problema de demarcação das fronteiras conceituais: a tensão entre a universalidade do conceito e a diferença que o desestabiliza. De quais "Américas" estamos falando, quando está em questão o pensamento dos intelectuais de fins do século? América Ibérica, América Hispânica, América Latina, América do Sul, América Central, América do Norte? Trata-se da pluralidade de significados desse significante vazio América, a realidade do espaço aberto que se traduz como um imperativo da diferença para a expressão identidade. E como essas diversas Américas estão implicadas na definição de outro significante vazio e oscilante que chamamos de Brasil?

Para dar maior mobilidade aos conceitos que estamos desenvolvendo neste artigo ou para poder expressar melhor a turbulência dos mundos que eles evocam - , lançaremos mão de algumas ideias de Jacques Derrida, especialmente a noção de exterior constitutivo que está diretamente relacionada a sua perspectiva da desconstrução. A ideia de relacionar a exterioridade e a interioridade da identidade é usada aqui como um critério metodológico de estruturação do artigo, tendo em vista que a exterioridade é o limite-mobilidade da transgressão, exterioridade sem a qual a própria identidade não se realiza. A exterioridade constitutiva denuncia a demarcação de uma vontade de autenticidade e de exclusividade ontológica das identidades. Significa dizer: quando falamos de exteriores constitutivos, o que temos em vista é articular as diversas demarcações identitárias da nação (e de seus outros) como realidades do suplemento e da diferença (DERRIDA, 1991, 2001). Derrida sugere que a desconstrução implica pensar a genealogia estrutural de certos conceitos e jogar com suas configurações exteriores e interiores. Qualquer conceito concebido como puro, sob o signo da desconstrução, é marcado por sua différance, pela sua exterioridade constitutiva (DERRIDA, 2001, p. 13). Essa exterioridade constitutiva pode ser um autor ou um conjunto de autores, como também possibilidades conceituais, cujos significados se situam para além e aquém da suposta essência daquilo que é nomeado. A escrita, nesse sentido, é um processo de rasura, na qual a inscrição se coloca sobre outra inscrição, sem que se apague completamente aquilo que ficou como o arquirrastro. Os textos, nesse caso, mais do que remeterem a um ou outro autor, formam uma rede na qual o autor é apenas um dos pontos de conexão de um mundo mais complexo. Para o historiador, a desconstrução, com o seu arcabouço conceitual, possibilita historicizar radicalmente realidades carregadas por oposições sem que elas se esgotem em um sentido pleno. Democracia e ditadura, brasileiro e não-brasileiro, americano e não-americano, antigo e moderno, monarquia e república, civilização e barbárie, imanente e transcendente, são algumas oposições que a operação desconstrutiva historiciza e as joga em posições nas quais os conflitos não se esgotam na dinâmica exclusivamente dialética, mas em uma explosão na qual toda e qualquer mônada é

uma totalidade sempre fracassada. 
apenas um operador de relação.

O movimento da différance, na medida em que produz os diferentes e os diferencia, é a raiz comum das oposições de conceitos que escandem nossa linguagem (DERRIDA, 2001, p. 14). Na différance, nenhum conceito, palavra ou qualquer enunciado primordial sintetiza ou comanda, a partir da presença autoral que configura o centro, o movimento textual das diferenças. O sentido, algo que o historiador busca compreender ao interpretar um texto é constituído de um tecido de diferenças, uma rede de remessas textuais a outros textos, uma transformação textual na qual cada termo supostamente simples é marcado pelo rastro de um outro, a interioridade presumida do sentido que é centrífuga, uma força direcional que se desloca sempre para fora de si.

Aquilo que empiricamente localizamos em um determinado momento - o devirtempo do espaço e o devir-espaço do tempo - , ou seja, a identificação do Brasil com a América Latina, era algo que estava atrelado não somente a uma urgência de limitação identitária entre América e Europa, como também em relação às duas Américas em um processo de escrita que manteve - apesar do desejo de plenitude de consciência autoral sua dispersão.0

\section{O Ocidente ao Sul do Equador: a América Hispânica no contexto de debates brasileiro em fins do século XIX e início do século XX}

Falar nas Américas é evocar o Novo Mundo, aquele mesmo que serviu para demarcar a Europa como Velha e que, durante longo período, esteve entre as grandes utopias e ilusões da humanidade europeia (CANCELLI, 2004, p. 111-112). Afinal, como sugeria Eduardo Prado (1906a, p. 14) depois da descoberta da América, "ficou o gênero humano [sic] sabendo que, ao oeste da Europa, além do Oceano tenebroso, havia outro mundo". Não somente havia outro mundo, como esse outro invadiria as discussões dicotômicas sobre civilização (ou cultura), humanidade e natureza pelos próximos séculos. Dicotomia que acompanhou pensadores nos dois lados do Atlântico desde o descobrimento da América pelos europeus, o Velho e o Novo eram partes de uma "mentalidade esquematizante e apaixonada, abstrata e polêmica, ora contra o Velho, ora contra o Novo Mundo" (GERBI, 1996, p. 17).

Joaquim Nabuco, ao fazer a comparação entre essas constituições das Américas, disse em 1895, que "nós", os brasileiros, "pertencemos à América pelo sedimento novo, flutuante do nosso espírito, e à Europa, por suas camadas estratificadas" (NABUCO, 2005, p. 39). Os predicados mais móveis da identidade se encontravam no lado de cá do Atlântico, onde a realidade do novo era um imperativo da própria identificação nacional. 0 pensamento finisssecular no Brasil apresentava um problema para si: qual era a parte da América (e do Brasil) na civilização, para usarmos a expressão de uma conferência proferida por Joaquim Nabuco em 1909 (NABUCO, 1949). 
Quando o historiador Manoel Bomfim escreveu, em 1903, América Latina: males de origem, ele dedicou seu trabalho ao estado onde havia nascido: Sergipe. Tal dedicatória não causaria surpresa para o leitor se ela não fosse complementada pelo seguinte predicado: "ao pedaço de terra americana em que nasci" (BOMFIM, 2005, p. 7). Manoel Bomfim foi um dos primeiros autores a sistematizar a ideia de que o Brasil deveria ser compreendido não isoladamente, mas em relação com a América Latina em sua totalidade. Os problemas de desenvolvimento e de realização plena dos países latinos dependiam da superação do que ele denominava "parasitismo ibérico". De qualquer modo, para o autor, pensar os problemas do Brasil somente faria sentido se conjugado com a totalidade da América Latina e de sua relação com os conquistadores ibéricos. O autor, de fato, comparou a América com o restante da civilização em uma linguagem não muito otimista. Para o escritor, os "povos sul-americanos se apresentam, hoje, num estado que mal lhes dá o direito a ser considerados povos civilizados" (BOMFIM, 2005, p. 53). As nações latino-americanas, como partícipes diretamente da "civilização ocidental, pertencendo a ela, relacionados diretamente, intimamente a todos os outros povos cultos, e sendo ao mesmo tempo dos mais atrasados, e, por conseguinte, "dos mais fracos", eram "forçosamente infelizes" (BOMFIM, 2005, p. 53).

Se até os anos 70 e 80 do século XIX a discussão em torno da identidade nacional no Brasil era predominantemente, quando não exclusivamente relacionada à Europa, mais especificamente a Portugal, Inglaterra e França, a virada do século demarcou um momento de maior turbulência em que a circunscrição fronteiriça àquelas escalas identitárias tornouse insuficiente para dar conta do problema da identidade nacional pensada no Brasil. Além da Europa, as Américas, tanto Latina quanto Anglo-Saxônica, estavam na agenda dos debates dos intelectuais que tinham em mente estabelecer uma identidade na condição de um interior constitutivo da nação, quando o que se conseguiu foi um acúmulo de interiores transitivos, ou seja, de definições provisórias dos diversos seres nacionais e continentais que se realizaram como suplementares.

Crucial para a demarcação da ideia de Ocidente e da sua utilização ao longo deste artigo é a compreensão que os autores tinham acerca do papel do Brasil e das Américas na civilização. Como pensava Araripe Júnior (1963a, a p. 499): "Esse frêmito de subjetivismo nacional não tardará em converter-se num aumento de força coletiva. E então não será surpresa para nós a glorificação estética deste grupo de nações", o qual, para o autor, "parece destinado a reproduzir em outros moldes a civilização que nos legaram as raças educadas no verbo latino". Araripe pensava que o Ocidente não passava por uma decadência nem pelo crepúsculo dos povos, mas por um "frêmito que percorre o universo" e que demarcava a "entrada triunfal de uma nova fase da civilização" (ARARIPE JÚNIOR, 1963b p. 95). Entre outros, seu pensamento sugeria a exigência de conceber tal período como um momento crucial de definição dos marcos civilizacionais do Ocidente, no qual as Américas (tanto anglo-saxônica quando latina) estavam como que na disputa em torno da primazia 
ontológica ou do monopólio universal de definição do que era a própria civilização ou daquilo que se poderia ensinar para o Velho continente.

Graça Aranha (1969, p. 827), do mesmo modo que Araripe Júnior - ainda que com algumas impressões diferentes sobre a repercussão do verbo latino nas Américas - afirmou que "tudo nos liga, a nós brasileiros, ao gênio romano. O vaso onde se cozinha a nossa nacionalidade foi fundido na forma latina, e quem nos impele é a força motora desse gênio do Ocidente europeu, perpetuamente criador".

Araripe, Bomfim e Aranha eram intelectuais que tinham como centro de suas reflexões o lugar da América Latina na civilização ocidental. Negligenciar tal limite conceitual seria não levar em consideração o aspecto importante de que, antes de qualquer discussão difusionista a respeito da dicotomia lado de lá versus lado de cá, havia interesse desses autores em compreender a América em termos civilizacionais, incluindo tanto a América Hispânica quanto a América Portuguesa. Ainda que suas reflexões tivessem uma parte importante do seu recorte empírico no Brasil, eles as faziam relacionando-o com outros países da América Latina, o que demonstrava que havia um problema comum denominado América Latina, cuja relação com a Europa, ora de aproximação, ora de distanciamento, implicava a herança latina naquilo que ela teria de positivo e de negativo na constituição das identidades. Quer dizer: na disputa do Novo Mundo estava em jogo, entre outras coisas, a definição não somente da civilização ocidental, mas de seu futuro. Saber se a ele pertenceria ou não a América Latina e se ela era ou seria efetivamente a herdeira da Europa, foram algumas das questões desbravadas pelos polemistas. Eduardo Prado não se furtou de pensar essas questões e sua inscrição na definição do que seria a civilização, de modo geral, e a civilização brasileira, em particular e os modos como a noção da América Hispânica foram mobilizados nesses jogos das identidades.

\section{Os dilemas do Brasil e da América Hispânica no horizonte de expectativas de Eduardo Prado $^{4}$}

Ao falarmos de América Hispânica enquanto parte do Ocidente no pensamento de Eduardo Prado, a primeira ideia que talvez apareça em mente é a dicotomia entre os dois quinhões da América Ibérica, a saber, entre o Brasil e a América Hispânica como dois referenciais distintos do Ocidente ao Sul do Equador. Essa bifurcação exige que enfoquemos outro exterior constitutivo até então silenciado: a Espanha. Nesse sentido, faz-se necessário definir de modo mais preciso o adjetivo que compõe aquela expressão - América Hispânica. Nada mais conveniente do que começarmos essa apresentação pela ideia de Espanha que Eduardo Prado elaborou, ainda mais se pensarmos que tal articulação implicou uma relação

\footnotetext{
${ }^{4}$ Uso o conceito de horizonte de expectativa tal como proposto por Koselleck (2006). Para um aprofundamento da discussão, ver, além de sua obra, a reflexão sobre tempo e sentido proposta por Rüsen (2015).
} 
de continuidade com a Europa, da qual o autor não pretendia se desfazer em sua projeção de um futuro de promessa de retorno ao passado.

Do ponto de vista da proposta do artigo, a referência à Espanha como um exterior constitutivo do Brasil pode causar certo estranhamento. Afinal, estamos lidando com as Américas e não com o significante Europa ou um de seus componentes identitários. Contudo, a presença deste outro exterior constitutivo tem a ver com os modos através dos quais o passado e o futuro das nações latino-americanas haviam sido pensados. Quais seriam os termos das rupturas e das continuidades com essa história que teria começado na outra margem do Oceano e em que medida a América, fosse portuguesa, fosse espanhola, seria um desdobramento do mesmo ou se seria o irromper de uma nova temporalidade? Além disso, apresentar a Espanha na América é uma maneira de tornarmos menos dicotômico o que aparece como exterior constitutivo do Brasil, porquanto traçar a identidade da América Espanhola sem recorrer ao ser hispânico seria uma abstração. Linhas acima indicamos algumas ideias de autores brasileiros que tentaram pensar os termos da continuidade e da ruptura com o mundo latino. Passemos agora para o pensamento de Prado.

A Espanha não foi pensada por Eduardo Prado de modo sistemático e recorrente como sujeito do ser europeu, como ele o fez em relação à Inglaterra e a Portugal. A Espanha era, juntamente com o reino de Camões, parte daquele espírito de doação, de auto-sacrifício e do "esforço parturiante" que havia criado nações na América. Somente a "fusão do sangue ibérico" com "o sangue índio e africano" poderia fazer florescer uma raça nas regiões equatoriais e tropicais, diferente dos holandeses e dos ingleses, "cujos filhos murchariam e feneceriam nos trópicos" (PRADO, 1906a, p. 71-72). A hibridização racial entre europeus, negros e índios na América teria feito a força cultural do americano frente à natureza. $O$ meio era inóspito, e a raça, hibridizada, era apenas um dos fatores de enfrentamento (vitorioso) sobre ele. Contra as teorias raciológicas, epistemologicamente em voga na Europa e nas Américas, Prado escreveu: "a tão falada indolência meridional não passa de um lugar comum. A inaptidão do homem dos climas quentes para o trabalho é uma exageração convertida em preconceito entre os homens do norte" (PRADO, 1902, p. 66)

Quando Espanha e Portugal colonizaram o Mundo que para eles e para os demais europeus era novo, a bandeira do catolicismo e das cruzadas ainda era conduzida pelos porta-estandartes de ambos os reinos. Na situação de singular-coletivo, Espanha (e Portugal) representavam gloriosamente um "inolvidável papel no mundo, papel superior a suas forças", ao criarem "na carta do globo esta imensa constelação de nações da América Latina" (PRADO, 1906b, p. p. 212). Constelação que levou as nações ibéricas a "fatalmente, entraram no seu declínio" (PRADO, 1906b, p. 212).

Na sua índole católica, Espanha não era vista pelo autor como uma nação cujo respeito devesse ser vilipendiado; pelo contrário, tal condição era um imperativo para a terra de Inácio de Loyola, um herói da humanidade em sua luta contra a "Renascença pagã" (PRADO, 1906a , p. 13). Como sugeria Prado, a perda de um império marítimo e colonial e a 
passagem dos espanhóis de potência de primeira ordem para um plano inferior não deveria ser motivo de condenação de sua religião (PRADO, 1906b, p. 212-213). Para o autor, a Espanha tinha sido um baluarte da fé. Em tempos de insegurança, guerras, fragmentação, sobretudo religiosa, ocasionada pela Reforma Protestante, o que mais perturbava "as almas daquele tempo" não era somente o interesse material que os levava para as "batalhas das armas e das ideias", fosse nos campos, fosse nas universidades e nos centros intelectuais, mas sim "o problema da alma humana na sua vida futura" (PRADO, 1906a, p. 15). A solução para esse problema da "corrente pagã da Renascença" se daria através dos "rochedos hispânicos, onde devia brotar o castelo de Loyola, a fonte da renovação religiosa do século" (PRADO, 1906a, p. 20).

A admiração de Eduardo Prado por Loyola e pela Espanha moderna e renascentista residia não somente no seu esforço cruzado contra o "paganismo", mas também no seu anseio de perenidade, a rocha diante da corrente de mar cada vez mais voraz ou, em termos mais ligados a uma ontologia do tempo, a prevalência do ser sobre o devir. Era a duração de mais de trezentos anos, de uma instituição que chegava até o momento presente, "decurso de tempo em que nasceram e morreram tantas coisas, tantos governos, tantas dinastias, tantas doutrinas e tantos ideais" (PRADO, 1906a, p. 27), o que era mobilizado pelo autor de modo mais significativo. A permanência diante de uma sequência de vidas e de mortes era a estabilidade almejada, o mesmo repouso que ele não encontrava nos regimes políticos e na sociedade republicana onde vivia. A realidade do catolicismo inaciano se apresentava como definitiva, dada de uma vez por todas para todos os tempos, qualidade do tempo que era não uma primazia ontológica da Espanha, mas do ser cristão católico (universal) que ela encarnava e do qual a América Latina era herdeira.

Se a Renascença contra a qual o renascimento religioso proporcionado por Loyola era pagã, a contemporaneidade era individualista e ateia, o que contribuía para enfraquecer os laços de solidariedade mantidos pelas instituições católicas até então. O imperativo categórico católico da obediência estava sendo abandonado: "esta palavra obediência é uma palavra antipática à anarquia do nosso tempo, em que há em todos nós o frenesi de mandar" (PRADO, 1906a, p. 57). A obediência era requerida nas Repúblicas, nesse espaço onde grassava o individualismo tirânico. Como os espanhóis no século XVI, era um imperativo para os latino-americanos enfrentarem a República, com a força moral maciça do catolicismo.

A Espanha permitia uma cumplicidade com a eternidade no pensamento pradiano, a memória onipresente da rocha como verdade independente dos mortais. A metáfora da rocha é elucidativa aqui. $O$ que ela poderia ser senão ser? A rocha é o que é e está ali. Todas as mudanças que nela pudessem operar-se seriam, durante séculos e séculos, combinações regradas de sua consistência fundamental, dada de uma vez para sempre. Essa quietude e fixidez eram fundamentais para o escritor, sobretudo ao evocar uma instituição religiosa ancorada em crenças atreladas ao triunfo sobre a morte - o cristianismo (DASTUR, 2002, p. 
25). Tratava-se do dogma paulino da morte da morte, ou nos termos da identidade nacional, da morte da república como retorno da monarquia.

Para escritores monarquistas e católicos, como Prado, a história religiosa da Espanha era a fonte de perenidade diante do devir. Segundo o autor, somente as "obras insensatas" eram feitas "de repente". As "criações dos sábios", ou seja, instituições como a Companhia de Jesus, eram "amadurecidas e longamente preparadas" (PRADO, 1906a, p. 34). Nas suas palavras: "o tempo não respeita senão as coisas feitas com o seu concurso" (PRADO, 1906a, 34). A sabedoria do tempo era a cumulatividade da experiência como fonte do ser, o tempo instituído pela Companhia que fazia a incerteza do hoje e do amanhã se subordinarem à tradição como promessa. Qualquer horizonte de expectativas estaria enraizado no campo de experiências do passado latino, o que fundia em termos identitários o passado da Espanha (e de Portugal), com os países da América Latina.

A Espanha, enquanto particular, expressava o universal "espírito de solidariedade próprio à humanidade e que se pode chamar o instinto de associação"(PRADO, 1906a, p. 50). O catolicismo espanhol apenas realizaria historicamente essa constituição do homem. Contra os males presentes da fragmentação e do individualismo, apresentava-se o instinto de associação, o estar juntos e todos os predicados supostamente solidários que daí emanavam na condição de unidade cristã. Ordens religiosas como a Companhia eram, no pensamento do escritor, um produto natural e espontâneo da religião, encontradas tanto no budismo como entre os muçulmanos (PRADO, 1906a, p. 50). No catolicismo, porém (a conjunção adversativa que dava a mais-valia de ser ao cristianismo católico), "elas representam um papel moral que nunca desempenharam noutras religiões", a constituição de "verdadeiras associações de seguro da salvação das almas" (PRADO, 1906a, p. 50).

O mundo de Prado, suficientemente secularizado, sobretudo diante dos regimes republicanos, era um universo de "prazeres e de perigo", onde a prática da virtude era um imperativo para estancar a demolição dos valores e reconstituir a justiça do tempo por meio da experiência. As ordens religiosas e a Companhia de Jesus eram o seu melhor exemplo, "a vanguarda da Igreja" e, "se pudéssemos comparar as cousas da religião às da política, diríamos que elas são o partido exaltado do Catolicismo"(PRADO, 1906a, p. 51). A Espanha cumpria sua missão na história. Sua verdade exemplar era a afirmação do ser católico como garantia para o eterno, contra as ondas devastadoras do paganismo. Contra a república, a força da fé como uma apólice para a plenitude do ser.

Exposta tal ideia acerca da Espanha no pensamento de Eduardo Prado e daquela que era considerada a sua principal instituição, isso significava que as comunidades imaginadas na América Hispânica eram nações e garantidoras potenciais do ser? Essa é uma questão crucial para a compreensão do pensamento pradiano em relação a esse exterior constitutivo do Brasil. Se Espanha e Portugal haviam se assemelhado em termos de colonização e de criação de instituições perenes através do catolicismo, em quê o Brasil se diferenciava daquelas nações hispano-americanas como um todo? Era somente a língua o fator de 
distinção do mesmo-outro nessa relação, já que o catolicismo era um artefato cultural comum tanto às Américas portuguesa e hispânica?

Como corolário lógico, seria correto pensar as nações hispano-americanas como herdeiras da colonização espanhola, o que significa afirmar que suas instituições eram portadoras dos mesmos predicados de sua ex-metrópole. Isso, seguramente, aproximaria seu ser nacional ao Brasil, porquanto haveria entre eles uma identidade que precederia sua constituição como nações.

Escritos de Prado sobre o conflito entre Espanha e Estados Unidos pela posse e independência de Cuba em 1898 eram indicativos de que a Espanha, "pobre, mas inabalável", havia deixado marcas permanentes na história latino-americana, o que

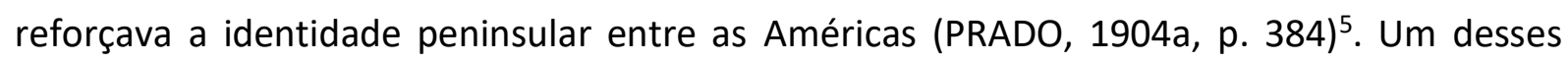
traços seria a relação racial em Cuba, onde sob "o tão vilipendiado jugo espanhol, não há ódios de raças e, em pé de igualdade, negros e brancos entram no mesmo teatro e na mesma igreja" (PRADO, 1904a, p. 377). Diferentemente dos Estados Unidos, principal objeto de sua comparação, não havia em Cuba "desprezo pela gente de cor", ao contrário da "grande República, sob o domínio da religião cristã e da liberdade" (PRADO, 1904a, p. 377), onde os negros eram esmagadoramente desprezados pelos brancos. Se os Estados Unidos eram efetivamente livres, o negro lá deveria ser tratado, de acordo com o autor, "com muito mais humanidade do que na malfadada e mal governada colônia dos cruéis espanhóis" (PRADO, 1904a, p. 377).

A comparação entre Cuba e Estados Unidos e, de modo subjacente, entre a colonização espanhola e a colonização britânica, indica que Prado pensava a América Latina, pelo menos nos seus aspectos raciais, de modo similar em termos identitários, situação que já havia aparecido algumas linhas acima, quando tratamos de investigar aquela ideia de um amálgama entre as raças americanas como diferencial de sua identidade. No caso apresentado, tratava-se da afirmação de uma hibridização responsável pela criação da civilização nos trópicos; aqui, a questão girava em torno não do domínio da raça sobre uma natureza inóspita e hostil, o que fazia o sul-americano sobrepor-se virilmente à natureza, mas da sua pacificidade e da possibilidade de seu convívio de modo pacífico diante das diferenças raciais. Em linhas gerais, uma espécie de democracia das raças que assinalava uma identidade latina da América.

Retomemos a ideia do esforço parturiante. A Espanha havia se sacrificado e, a exemplo de Portugal, criado nações. Diferentemente do espírito americano anglo-saxão, de violência e de ódio, o espírito latino, "mais ou menos deturpado através dos séculos e dos amálgamas diversos do iberismo", era um "espírito jurídico" que "conserva sempre um certo respeito pela vida humana e pela liberdade" (PRADO, 1961, p. 175).

\footnotetext{
${ }^{5}$ Capelato sugere que a independência de Cuba foi uma razão de aproximação entre os intelectuais hispanoamericanos e os espanhóis de fins do século. Ver: CAPELATO (2003).
} 
Se o respeito à vida humana e à liberdade eram predicados comuns na América Ibérica, talvez pudéssemos afirmar a identidade absoluta entre Brasil e América Hispânica, na medida em que o autor via essas mesmas qualidades no Brasil de Dom Pedro II. O exterior constitutivo seria o mesmo para os dois, cuja diferença seria manifesta na superfície da língua falada e na divisão geográfica. Mas Prado via uma ameaça republicana interna e externa, consubstanciada em um presente ameaçador de desagregação do ser. O contraste com a América Hispânica, portanto, deveria ser amplificado, de modo que qualquer identidade republicana do continente fosse imediatamente afastada do que seria o ser do Brasil. A tensão entre identidade e alteridade, que marcou suas ideias em relação à Europa, também estava presente na definição do exterior constitutivo latino-americano, uma ambiguidade que não se resolveu em seus escritos.

Quando Eduardo Prado traçou seus escritos sobre a América Espanhola, ele não o fez de modo a prestigiá-la na sua totalidade, tal como fizera no caso cubano e no caso da sua ancestral ibérica quando escreveu sobre a Companhia de Jesus e sobre a Guerra de Cuba. Tratava-se, nos termos de Eliade (1988, p. 120), de um modo tipicamente mítico de pensar, na medida em que Prado recusava a irreversibilidade do tempo por meio do ritual, o que anularia o tempo profano e cronológico para recuperar o tempo sagrado da integração, uma relação temporal de corte, de ruptura que demarcava o sacro e o profano do ser latinoamericano.

A razão pela qual podemos pensar essa diferença residia na crença do autor de que o Brasil era superior às demais nações latino-americanas, "aquela terra que, na América, é a mais bela, a maior da raça latina" (PRADO, 2003, p. XX). A pergunta que colocamos é: se as nações latino-americanas preconizavam o respeito à liberdade e à vida humana, se elas eram católicas, herdeiras daquela tradição de "loucura" que levou os espanhóis a criarem as mais diversas instituições, se elas ainda eram, na sua índole, pacíficas e fortes, por que o Brasil haveria de ser a civilização mais bela e a maior da raça latina na América?

Ele o seria apenas por uma sentença dogmática nacionalista? Não seria plausível descartar a ideia de uma proposição dogmática nessas circunstâncias (como diversas outras que o autor enunciou). Não obstante, gostaríamos de explorar um pouco mais essas ambiguidades no pensamento do autor, ainda mais em se tratando de um pensamento nacionalista cuja universalidade reivindicava os predicados da beleza, do bem, do ser e do uno.

Algumas das razões que levaram Prado a se posicionar favoravelmente ao Brasil monárquico e contrário à América Hispânica republicana era a própria sombra do Brasil republicano. A identidade entre as repúblicas atemorizava o autor, que via ameaçada a identidade ibérica originária da América Latina. Além disso, outro fator importante foi a passagem do Brasil colonial para uma monarquia e não para uma república, como havia acontecido com as nações hispânicas da América. Esse diferencial era uma condição da superioridade da civilização brasileira, personificada, sobretudo, na figura mítica de Dom Pedro II. O que fica em aberto nessas circunstâncias é a tensão entre o desejo de eternidade 
e a consciência de uma ameaça que, se fosse efetivamente ineficaz, não precisaria ser temida.

As nações hispânicas da América, na sua maioria, eram, a exemplo da República recém instalada no Brasil, pensadas pelo autor como repúblicas mal-sucedidas política, cultural e economicamente. Desde o seu rompimento com o domínio colonial, tais nações eram as Repúblicas militares, dos pronunciamientos que nem sequer davam qualquer durabilidade política para o subcontinente. Portanto, a exemplo do Brasil republicano, todas as nações da América Hispânica eram reféns de uma instituição exterior a elas. Se liberdade e respeito à vida eram qualidades precípuas da Hispano-América, seria evidente que a tradição republicana, difundida nas Américas pelos Estados Unidos, exótica, não faria parte do seu ser. Tais ideias não eram completamente novas. Antes de Prado, seria possível encontrar escritos de outros autores sobre a América Latina que as colocavam em uma espécie de instabilidade constitutiva.

Almeida Garret, contemporâneo dos processos revolucionários na América Latina, escreveu sobre elas o seguinte: "a embriaguez das facções, a discórdia civil, a infrene demagogia devastam esses países, que se não libertaram da tirania... senão para sofrer mais cruéis tiranos" (ALMEIDA GARRET, 1904, p. 47). Tocqueville não foi diferente em sua apreciação das "nações sul-americanas":

Estranha perceber as novas nações sul-americanas agitarem-se, há um quarto de século, em meio a revoluções que recomeçam a cada instante e, a cada dia, esperase vê-las voltar ao que se chama o estado natural. Mas quem pode afirmar que essas revoluções não sejam atualmente o estado mais natural dos espanhóis da América do Sul? Nesses países, a sociedade debate-se no fundo de um abismo, do qual seus próprios esforços não são capazes de fazê-la sair (TOCQUEVILLE, 1979, p. 234).

Os escritos de Garret e de Tocqueville contribuem para que possamos pensar o que Eduardo Prado questionava ao se referir à América Hispânica. Sair de uma tirania para outra tirania, do modelo colonial dependente para a ainda dependente república era essencializar a tirania, convertê-la em uma qualidade permanente daquelas nações ou converter em ser o nada, o abismo no qual se debatia e do qual não se saia, para retomarmos as palavras de Tocqueville.

O exterior constitutivo, esse outro componente nacional que não se coadunaria com a tradição brasileira (e também com a tradição latino-americana) era, em grande medida, não simplesmente a forma republicana per se, mas a violência, a mundanização, a escravidão nacional, os macaquismos constitucionais (cópias), a arbitrariedade, a crise política, o desequilíbrio, a instabilidade, a ruína e a corrupção mais do que a geração. Enfim, qualidades que estavam relacionadas à forma republicana, especialmente em duas circunstâncias de colapso: no caso hispano-americano e no Brasil pós-1889. Nabuco, em 1891, afirmou que os americanos estavam condenados à mais terrível das instabilidades, e "é isso o que explica o fato de tantos sul-americanos preferirem viver na Europa" (NABUCO, 2005, p. 39). Ou ainda, 
que o Brasil estava no "redemoinho republicano da América... um cadáver girando no sorvedouro da anarquia" (NABUCO, 2006, p. 292).

Prado entendia que as nações latino-americanas haviam se corrompido quando se tornaram republicanas. Estabelecia-se um hiato temporal que demarcava o início de uma escravização coletiva, nacional, quando a América Hispânica havia se tornado independente, ou seja, republicana. A sua situação pós-colonial nada mais seria do que uma relação de continuidade com uma tradição alheia aos valores ibéricos. Em termos de suspensão do devir, a temporalidade do ser da nação dava-se simultaneamente no hiato e na continuidade. Hiato como rompimento com a matriz colonial (escrava) e o prosseguimento de um tempo de subordinação. O resultado final era o mesmo: dependência e ausência de autonomia nacional.

A América Hispânica, nesse intervalo, era uma espécie de não-ser. Seu passado, por mais que fosse ibérico, diferia do Brasil por ter sido colonizado na sua totalidade até tornarse república. Quando deixou de ser colônia, tornou-se república. No esquema evolucionista de Prado, a América Hispânica teria passado de uma dominação a outra. A Monarquia, que era a sua matriz civilizacional, poderia ser um horizonte de expectativas para a América Hispânica, mas não era a sua realidade, nem passada, nem presente. Esse hiato não poderia ser modelo para o Brasil a não ser na condição de tornar também o Brasil legatário daquela tradição ibérica de catolicismo. O Brasil se tornaria, se continuasse monárquico e católico, exemplar não somente para si mesmo, mas também para o mundo civilizado. A América Hispânica poderia ser uma espécie de história a priori, uma profecia para o futuro sem qualquer experiência no passado dentro do próprio continente, tal como ocorria com o Brasil no presente. É como se houvesse um passado potencial (latino) a ser desenvolvido no futuro.

Nesse sentido, Eduardo Prado divergia da concepção sustentada pelo seu compatriota e contemporâneo Manoel Bomfim, que atribuía o problema do subdesenvolvimento da América Latina ao parasitismo das metrópoles, ou seja, a responsabilidade do atraso não às Repúblicas, mas às metrópoles - Espanha e Portugal -, que colonizaram a América Latina. Não que Bomfim fosse um positivista, defensor da República. A exemplo de Prado, o autor via na República positivista uma cópia malelaborada dos Estados Unidos. Sua América Latina: males de origem, escrita em 1903 e publicada em 1905, atacava para todos os lados, tanto através de uma crítica à aproximação do Brasil em relação aos Estados Unidos, como também à relação passada do Brasil com a Europa (BOMFIM, 2005).

Para Prado, o México era deprimente e opressor contra a Guatemala, que por sua vez mantinha guerras contra El Salvador, inimigo da Nicarágua. A história recente de todas essas nações era um "rio de sangue", um "contínuo morticínio" (PRADO, 1961, p. 8-9), cuja cadeia de ódios e rancores se estendia à totalidade das Repúblicas sul-americanas, posto que, para o autor, havia um ódio mortal entre Colômbia e Venezuela, Peru, Equador, Chile, Argentina e Uruguai. Não havia harmonia entre tais nações: "a comunidade de origem, a raça, a língua, a 
religião idênticas não são suficientes garantias da conservação da harmonia" (PRADO, 1961, p. 5). Como uma maneira de exemplificar tal fragmentação, Prado pensava no caso do Chile e do Peru: "não há no mundo", disse o autor, "dois povos que tenham ódio recíproco tão profundo como os chilenos e os peruanos, e ambos descendem de espanhóis, falam a mesma língua, tem a mesma religião. A unidade certamente desaparecerá" (PRADO, 1961, p. 5). A ditadura, no Peru, na Bolívia, no Brasil, na Argentina e em toda a parte, era "o enfraquecimento nacional, porque é o regime em que o poder pode tudo e em que o cidadão nada vale" (PRADO, 2003, p. 40). Ainda de acordo com o autor, "a certeza de que nada é impossível a quem tem o mando é a noção mais deprimente e corruptora que um povo pode aprender. Não há caráter nacional capaz de resistir à ação dissolvente desta ideia" (PRADO, 2003, p. 40). Significava também dizer que a República era "coisa que na América do Sul quer sempre dizer o confisco de todas as liberdades" (PRADO, 1904b, p. 8). Ainda mais: "nunca vimos sinal de liberdade em nenhum dos desorganizados acampamentos militares que, na América Espanhola, tem a alcunha de Repúblicas livres" (PRADO, 1904c, p. 49).

Nos Fastos da ditadura militar no Brasil, a ideia de uma inversão temporal ficou evidente nessa passagem, em que o escritor comparou o Brasil ao Paraguai:

\footnotetext{
Infeliz Paraguai! Bem vingado estás tu neste momento vendo que o Brasil, teu orgulhoso vencedor de outrora, é hoje o imitador do que tu foste há trinta anos! Os brasileiros, que tanto desprezavam os costumes semibárbaros da política paraguaia, têm hoje em casa o que tanta compaixão lhes inspirava na casa dos seus inimigos (PRADO, 2003, p. 36).
}

Rio de sangue, depressão, individualismo, indiferença, opressão, guerras, morticínio, ódio recíproco. A fragmentação e as diferenças irreconciliáveis representavam, para Prado, a perda de valores que até então vigoravam na civilização. A América Latina era o precedente histórico da diferença em relação à monarquia que se transfigurara em identidade republicana. A republicanização do Brasil o empurrava para a perda de um referencial ontológico em relação aos outros americanos latinos. A República consubstanciava essa crise de valores. Caminhar em sua direção seria a vereda para o abismo. A América Hispânica republicana era um exterior constitutivo do Brasil que se colocava como um imperativo da negação: o que não era a civilização brasileira? Categoricamente, ela não era, nem deveria ser, a América Espanhola. Seu ser era inalcançável porque era uma aporia: quando a América Hispânica era monárquica, ela era dependente e colonial. Quando ela se tornou independente, converteu-se em república. República e autonomia eram, no contexto latinoamericano, termos inconciliáveis.

A unidade à qual Prado se referia não era delimitada somente àquelas nações, mas também ao Brasil que se republicanizava e que estava ameaçado de decompor-se. Havia não somente uma história recente, mas conhecida dos brasileiros, que apontava para aquele caminho. O exemplo republicano das nações coirmãs ibéricas indicava que seu passado (recente) deveria ser o horizonte de expectativas do Brasil, não expectativas e esperanças no 
sentido de imitar o seu modelo; pelo contrário, de tomar o seu passado recente como o padrão daquilo que o Brasil deveria evitar, um gênero de imperativo ontológico-moral às avessas: o não-dever-ser. Ou, para inverter a lógica temporal, a necessidade de ver no presente republicano da América apenas a experiência mal-sucedida em termos civilizacionais que apontava não para o futuro, mas para o passado recente. Ser republicano, para o autor, nesse sentido era não ser progressista, porquanto o modelo de inspiração presente não era o Brasil monárquico - com o qual ele pretendia manter uma relação de continuidade - mas um conjunto de modelos anteriores, que faziam parte do ser hispânico da América e que era encontrado na subordinação nacional à metrópole. Talvez dois oximoros possam expressar essa relação de presente, passado e futuro das Américas. Prado era um progresssista reacionário, na medida em que o retorno ao passado é que permitiria às nações da América perdurarem nos rumos do progresso. Além do mais, era um defensor da autonomia heterônoma da nação, pois seu modelo de autonomia nacional não estabelecia ruptura com uma norma que vinha de fora daquilo que se definia como nação enquanto tal.

\section{Considerações finais}

O problema que investigamos no presente artigo não é completamente novo. Benedict Anderson, em seu livro clássico Comunidades imaginadas, sugeriu que a compreensão das raízes culturais da nação moderna passava pela sua relação com os imaginários religiosos e, em especial, com o tema da morte. Ao evocar essa relação, Anderson afirmou que as mundividências religiosas tradicionais, tais como o cristianismo, o budismo e o islamismo tinham uma preocupação com o homem no cosmos e com a contingência da vida, o que implicava uma resposta imaginativa, em termos ontológicos, para o "fardo avassalador do sofrimento humano - a doença, a mutilação, o desgosto, o envelhecimento e a morte" (ANDERSON, 2005, p. 32). Segundo o autor, a nação deve ser pensada, para que possa ser compreendida, em termos de um imaginário comum com as comunidades religiosas e, no caso ocidental, com a Cristandade. Anderson deu um passo importante para pensar a nação em termos de articulação com o tema da temporalidade. Morte, catástrofe, envelhecimento, contingência e limite são conceitos que nos remetem para o tema do devir em sua radicalidade. Apesar de não termos as mesmas pretensões genealógicas de Anderson em mapear a origem da nação, não seria plausível deixar de reconhecer uma cumplicidade de nossa reflexão com sua tese. Nossa demarcação, em termos empíricos foi um pouco menos ambiciosa. Tratamos de investigar os escritos de um intelectual que teve como centro permanente de referência o Brasil em termos identitários nacionais e a ameaça de sua dissolução diante da realidade da corrosão e da finitude consubstanciados em uma ideia de república, tanto da recente república brasileira quanto daquelas vizinhas da América Hispânica. 
O autor vivia o que seria um período de fragmentação da família, das instituições, da política, da religião e da própria ideia de civilização. Como uma maneira de encontrar novo sentido para o que era compreendido como cultura ocidental. Em termos de temporalidade da nação, o autor estava frente a frente à ideia de que nada do que havia se constituído permaneceria sub specie aeternitates, e que aquilo que potencialmente viria a se configurar como o ser era apenas a sua possibilidade de ser, a primazia conferida ao devir como disjunção entre o pensamento e o ser. Tratou-se de uma crise de sentido histórico que estava encontrando seus próprios limites em termos de realização. Quando Eduardo Prado pensou o Brasil e a América Hispânica, ele o fez tendo como lastro de seu pensamento a questão da decisão presente que implicava pensar as expectativas, as experiências, os cortes, as continuidades, as repetições. E com elas, um mundo que, para ele e para muitos de seus contemporâneos, desagregava-se.

\section{Referências}

ANDERSON, B. Comunidades imaginadas. Lisboa: Ed. 70, 2005.

ARANHA, G. A civilização latina e a alma brasileira. In: ARANHA, G. Obras completas. Rio de Janeiro: Instituto Nacional do Livro, 1969.

ARANHA, G. A civilização latina e a alma brasileira. In: ARANHA, G. Obras Completas. Rio de Janeiro: Instituto Nacional do Livro, 1969. p. 825-830.

ARANHA, G. Canaã. Rio de Janeiro: Ediouro, [s.d].

ARARIPE JÚNIOR, T. Americanismo. In: COUTINHO, A. (Ed.). Obra crítica de Araripe Júnior. Rio de Janeiro: Casa Rui Barbosa/Ministério da Educação e Cultura, 1963a, p.93-100.

ARARIPE JÚNIOR, T. O Brasil intelectual. In: COUTINHO, A. (Ed.). Obra crítica de Araripe Júnior. Rio de Janeiro: Casa Rui Barbosa/ Ministério da Educação e Cultura, 1963b, vol. 3, p. 497-502.

BOMFIM, M. A América Latina: males de origem. Rio de Janeiro: Topbooks, 2005.

BROCA, B. A vida literária no Brasil: 1900. Rio de Janeiro: Academia Brasileira de Letras/José Olympio, 2005.

CANCELLI, E. A América do desejo: pesadelo, exotismo e sonho. História. São Paulo, n.23 (12), p.111-132, 2004. https://doi.org/10.1590/S0101-90742004000200007

CAPELATO, M. H. A data símbolo de 1898: o impacto da independência de Cuba na Espanha e Hispanoamerica. História. São Paulo, n.22(2), p.35-58, 2003. https://doi.org/10.1590/S0101$\underline{90742003000200003}$

DASTUR, F. A morte: ensaio sobre a finitude. Rio de Janeiro: DIFEL, 2002.

DERRIDA, J. Margens da filosofia. Campinas: Papirus, 1991.

DERRIDA, J. Posições. Belo Horizonte: Autêntica, 2001.

ELIADE, M. Aspectos do mito. Lisboa: Ed. 70, 1988. 
GARRET, A. Portugal na balança da Europa: do que tem sido e do que ora lhe convém ser na nova ordem de coisas do mundo civilizado. Lisboa: Livraria Moderna, 1904.

GERBI, A. O Novo Mundo: história de uma polêmica. São Paulo: Cia. das Letras, 1996.

KOSELLECK, R. Futuro passado. Rio de Janeiro: Contraponto, 2006.

LEVI, D. A família Prado. São Paulo: Cultura 70, 1974.

NABUCO, J. Minha formação. São Paulo: Martin Claret, 2005.

NABUCO, J. Diários: 1873-1909. Rio de Janeiro: Bem-Te-Vi, 2006.

NABUCO, J. Pensamentos soltos, Camões e assuntos americanos. São Paulo: Instituto Nacional do Livro, 1949.

PRADO, E. A ilusão americana. São Paulo: Brasiliense, 1961.

PRADO, E. A Espanha. In: PRADO, E. Coletâneas. São Paulo: Escola Tipográfica Salesiana, 1904a, p.366-385.

PRADO, E. A crítica republicana. In: PRADO, E. Coletâneas. São Paulo: Escola Tipográfica Salesiana, 1904b, p.7-18.

PRADO, E. A crítica republicana. In: PRADO, E. Coletâneas. São Paulo: Escola Tipográfica Salesiana, 1904c, p.49-69.

PRADO, E. O catolicismo, a Companhia de Jesus e a colonização do Novo Mundo. In: PRADO, E. Coletâneas. São Paulo: Escola Tipográfica Salesiana, 1906a, p. 7-101.

PRADO. E. O Dr. Barreto e a ciência: caso curioso de intolerância religiosa no século XX. In: PRADO, E. Coletâneas. São Paulo: Escola Tipográfica Salesiana, 1906b, p.105-273.

PRADO, E. Viagens: Sicília, Malta e Egito. São Paulo: Escola Tipográfica Salesiana, 1902.

PRADO, E. [Frederico de S.]. Fastos da ditadura militar no Brasil. São Paulo: Martins Fontes, 2003.

RÜSEN, J. Teoria da história: uma teoria da história como ciência. Curitiba: Editora UFPR, 2015.

TOCQUEVILLE, A. A democracia na América. In: Os pensadores. São Paulo: Abril Cultural, 1979.

VENTURA, R. Estilo tropical. São Paulo: Cia. das Letras, 1991.

VERÍSSIMO, José. História da literatura brasileira. Brasília: Ed. da UnB, 1963.

Recebido em: 08/11/2019.

Aceito em: 19/02/2020. 